\title{
Combustion of dried animal dung as biofuel results in the generation of highly redox active fine particulates Ian S Mudway* ${ }^{\dagger 1}$, Sean T Duggan ${ }^{\dagger 1}$, Chandra Venkataraman², Gazala Habib², Frank J Kelly ${ }^{1}$ and Jonathan Grigg ${ }^{3}$
}

Address: ${ }^{1}$ Lung Biology: Pharmaceutical Science Research Division, School of Biomedical \& Health Sciences, King's College London, FranklinWilkins Building, 150 Stamford Street, London, SE1 9NH, UK, 2Department of Chemical Engineering, Indian Institute of Technology, Bombay, Powai, Mumbai-400 076, India and 3 Division of Child Health, Department of Immunology, Infection and Immunity, University of Leicester, PO Box 65, Leicester

Email: Ian S Mudway* - ian.mudway@kcl.ac.uk; Sean T Duggan - sean.duggan@kcl.ac.uk; Chandra Venkataraman - chabdra@che.iitb.ac.in; Gazala Habib - gazala@che.iitb.ac.in; Frank J Kelly - frank.kelly@kcl.ac.uk; Jonathan Grigg - jg33@leicester.ac.uk

* Corresponding author †Equal contributors

Published: 04 October 2005

Particle and Fibre Toxicology 2005, 2:6 doi:10.1186/1743-8977-2-6
Received: 07 February 2005

Accepted: 04 October 2005

This article is available from: http://www.particleandfibretoxicology.com/content/2/1/6

(c) 2005 Mudway et al; licensee BioMed Central Ltd.

This is an Open Access article distributed under the terms of the Creative Commons Attribution License (http://creativecommons.org/licenses/by/2.0), which permits unrestricted use, distribution, and reproduction in any medium, provided the original work is properly cited.

\begin{abstract}
Background: The burning of biomass in the developing world for heating and cooking results in high indoor particle concentrations. Long-term exposure to airborne particulate matter (PM) has been associated with increased rates of acute respiratory infections, chronic obstructive lung disease and cancer. In this study we determined the oxidative activity of combustion particles derived from the biomass fuel dung cake by examining their capacity to deplete antioxidants from a model human respiratory tract lining fluid (RTLF). For comparison, the observed oxidative activity was compared with that of particles derived from industrial and vehicular sources.
\end{abstract}

Results: Incubation of the dung cake particle suspensions in the RTLF for $4 \mathrm{~h}$ resulted in a mean loss of ascorbate of $72.1 \pm 0.7$ and $89.7 \pm 2.5 \%$ at 50 and $100 \mu \mathrm{g} / \mathrm{ml}$, respectively. Reduced glutathione was depleted by $49.6 \pm 4.3$ and $63.5 \pm 22.4 \%$ under the same conditions. The capacity of these samples to deplete ascorbate was in excess of that observed with diesel or gasoline particles, but comparable to that seen with residual oil fly ash and considerably in excess of all three control particles in terms of glutathione depletion. Co-incubation with the metal chelator diethylenetriaminepentaacetate inhibited these losses, whilst minimal inhibition was seen with superoxide dismutase and catalase treatment. The majority of the activity observed appeared to be contained within aqueous particle extracts.

Conclusion: These data demonstrate that biomass derived particles have considerable oxidative activity, largely attributable to their transition metal content.

\section{Background}

Approximately two billion people in the developing world use biomass fuels such as wood, crop-waste and dried animal dung, as their major source of domestic energy $[1,2]$. The burning of this material in open fires and stoves results in high concentrations of particulate matter (PM), carbon monoxide, nitrogen dioxide, as well as volatile and semi-volatile organic species in the indoor environment $[3,4]$. In homes where biomass burning occurs airborne particle concentrations are far in excess of 
those found in homes where it is not used as a heating/ cooking source, with $24 \mathrm{~h}$ average $\mathrm{PM}_{10}$ concentrations ranging between 200 and $5000 \mu \mathrm{g} / \mathrm{m}^{3}$ depending on the fuel type, stove and ventilation $[5,6]$. These concentrations are far in excess of the level considered safe for $\mathrm{PM}_{10}$ in outdoor air $-150 \mu \mathrm{g} / \mathrm{m}^{3} 24 \mathrm{~h}$ average [7].

An increasing body of evidence has linked exposure to indoor pollutants with increased rates of respiratory morbidity and mortality. Women and children exposed to high indoor PM concentrations have significantly increased rates of acute respiratory infections (ARI) [5,8$10]$, and women cooking over biomass fires for extensive periods have an enhanced risk of chronic obstructive pulmonary disease (COPD) and lung cancer [11,12]. In a recent study we found that lower airway cells from women and children exposed to biomass smoke contained significantly more carbonaceous material than age-matched subjects exposed to fossil fuel derived $\mathrm{PM}_{10}$ [13]. Whilst enhanced particle deposition in the airways is clearly important, the chemical and physical characteristics of airborne particles that contribute to their toxicity have not been firmly established, though particle size and surface area $[14]$, as well as acidity and composition $[15,16]$ have all been mooted as important determinants in this regard.

The capacity of inhaled PM to elicit damaging oxidation reactions in the lung and systemic circulation may account for many of the toxic responses observed in exposed individuals [17]. Certain transition metal components of PM are capable of catalysing oxidation reactions [18], as are quinones [19] resulting in the production of reactive oxygen species. An excessive production of these species can activate redox sensitive transcription factors regulating the expression of proinflammatory cytokines, leading to inflammation and tissue injury [20]. Measuring the capacity of PM to oxidise physiologically relevant molecules can therefore be used to provide a biologically relevant index of activity, integrating PM size, surface area and composition.

In this study we evaluated the oxidative activity of PM samples derived from the controlled burning of cow-dung cake using a traditional Indian cooking stove. These assessments were based on the capacity of dung cake particulate suspensions to deplete physiologically relevant antioxidants, ascorbate (AA), urate (UA) and reduced glutathione (GSH) from a synthetic model of human respiratory tract lining fluid. Previously we have used this model to investigate the nature of gaseous and particulate pollutant-antioxidant interactions at the air lung interface $[21,22]$. In addition we examined the extent to which any observed activity could be attributed to the metal or organic content of the dung cake particles.

\section{Results}

Three Teflon filters were supplied containing 0.86 (DC1), 1.20 (DC2) and $1.14 \mathrm{mg}$ (DC3) of $\mathrm{PM}_{2.5}$. Particle suspensions prepared from each of the three filters depleted AA from the synthetic RTLF in a dose dependent manner with a mean loss of $72.1 \pm 0.72$ and $89.7 \pm 3.7 \%$ AA at 50 and $100 \mu \mathrm{g} / \mathrm{m}^{3}$ respectively relative to the $4 \mathrm{~h}$ particle free control concentration. This loss of AA was significantly greater than that associated with an equal mass $\left(50 \mu \mathrm{g} / \mathrm{m}^{3}\right)$ of diesel $(6.4 \%)$, gasoline (5.2\%) or residual oil fly ash (ROFA) (53.9\%) particles (Figure 1). All of the tested PM samples were $\mathrm{PM}_{2.5}$, apart from the diesel and gasoline samples that were collected using a high volume cascade impactor as $\mathrm{PM}_{0.1-2.5}$. Of these particles ROFA had the smallest median diameter, 0.07-0.08 $\mu \mathrm{m}$ [23], with diesel and gasoline PM samples in the range 0.1-0.2 $\mu \mathrm{m}$ (Thomas Sandström, personal communication), with the dung cake samples displaying the largest median aerodynamic diameter, 0.6-0.8 $\mu \mathrm{m}$ [4]. These data further emphasise the reactivity of the DC samples, taking into account their lower surface area per unit mass, compared with the control PM samples. These AA losses were completely inhibited when the dung cake particles were co-incubated with $100 \mu \mathrm{M}$ DTPA (Figure 1).

GSH was also depleted in a dose dependent manner by the dung cake PM extracts, $49.6 \pm 4.3$ and $63.5 \pm 22.4 \%$ at 50 and $100 \mu \mathrm{g} / \mathrm{m}^{3}$ respectively. These losses were significantly greater than those observed with ROFA, which actually demonstrated a reduced loss of GSH compared with the particle free control, or the traffic derived samples, which depleted GSH 10.2\% (diesel) and 15.7\% (gasoline) (Figure 2). Notably, no loss in total glutathione was noted during the incubations suggesting that adsorption to the particle surface was not occurring to any great extent. Similar to the situation with AA, co-incubation with DTPA completely abolished the loss of GSH. Incubation with DTPA also prevented the background losses of both ascorbate $(-20.8 \pm 6.2 \mu \mathrm{M}$ - Figure 1$)$ and glutathione $(-47.4 \pm 6.1 \mu \mathrm{M}$ - Figure 2$)$ from the particle-free controls over the $4 \mathrm{~h}$ incubation. These losses were attributable to the presence of contaminating metal ions in the synthetic RTLF following Chelex-resin treatment. Urate was not depleted from the RTLF model by any of the particle types examined in line with our previous observations [21] (data not shown).

Further characterisation of the metal dependence of the oxidative reactions observed was performed using an AA only RTLF model. Individual AA consumption rates at 50 $\mu \mathrm{g} / \mathrm{mL}$ for each of the three dung cake extracts were similar: $13.7 \pm 0.15$ (DC1), $13.5 \pm 0.49$ (DC2) and $13.3 \pm 0.19$ $\mathrm{nM} / \mathrm{s}$ (DC3). Co-incubation with the metal chelator DTPA $(100 \mu \mathrm{M})$ significantly reduced the rate of AA oxidation: $6.5 \pm 0.36$ versus $13.5 \pm 0.27 \mathrm{nM} / \mathrm{s}$ for all three 


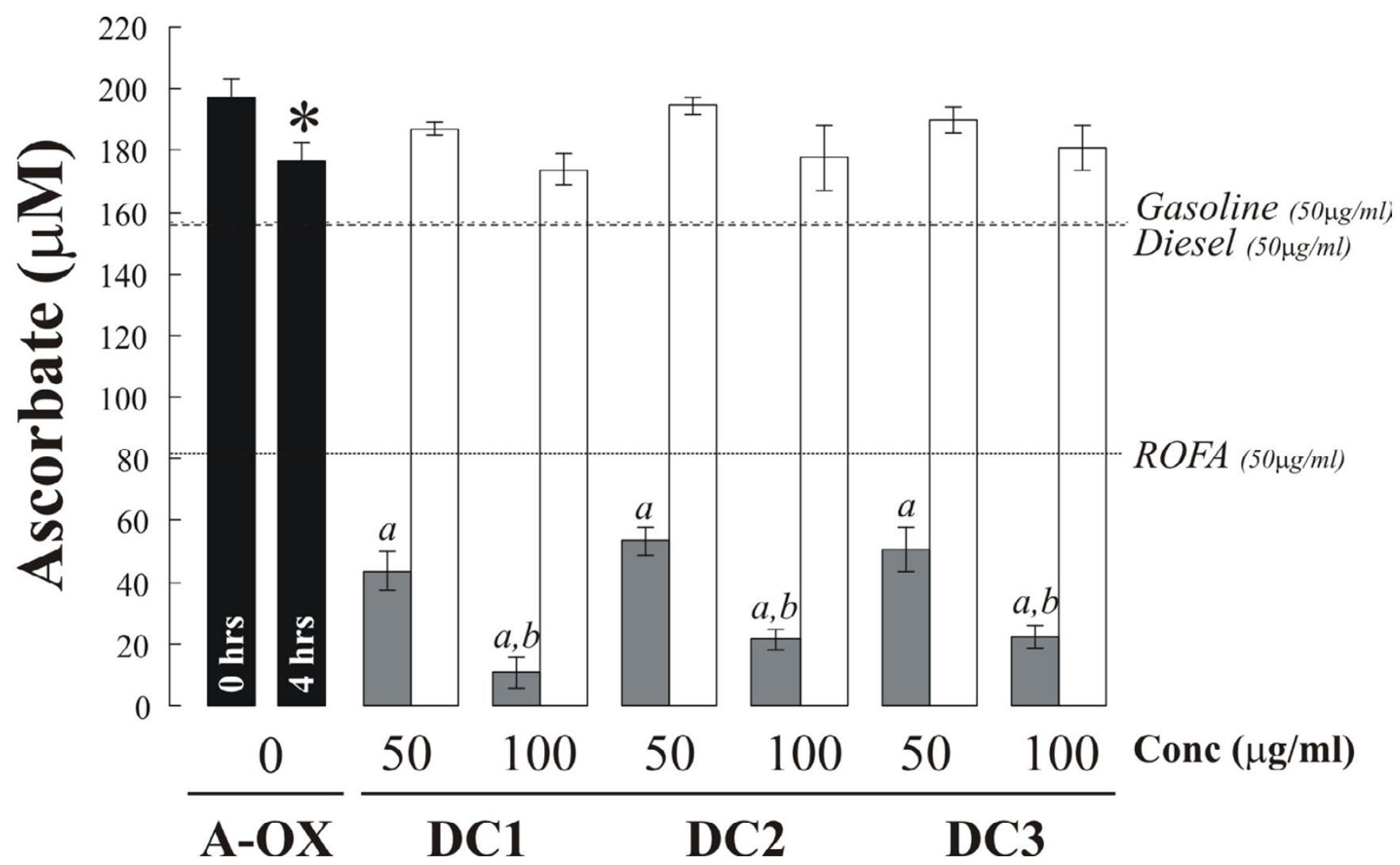

Figure I

AA remaining in synthetic RTLF following a $4 \mathrm{~h}$ incubation with three separate dung cake (DC) samples at 50 and $100 \mu \mathrm{g} / \mathrm{ml}(\mathrm{grey}$ bars) The impact of co-incubation with the transition metal chelator DTPA $(200 \mu \mathrm{M})$ is illustrated by the white bars. Pre $(0 \mathrm{hr})$ and post ( $4 \mathrm{hr}$ ) AA concentrations in the particle-free controls are illustrated in the black filled bars. The losses observed with $50 \mu \mathrm{g} / \mathrm{ml}$ doses of fresh diesel and gasoline PM $\mathrm{PM}_{0.1-2.5}$, as well as ROFA are also illustrated. Data represent the mean (SD) of 3 separate experiments: ' $a$ ' - indicates that AA concentrations after the $4 \mathrm{~h}$ incubation were significantly lower $(P<0.05)$ than the $4 \mathrm{~h}$ particle free control values; ' $b$ ' illustrates that the losses observed at $100 \mu \mathrm{g} / \mathrm{ml}$ are significantly greater than those seen at the lower $50 \mu \mathrm{g} / \mathrm{ml}$ concentration. The '*' illustrates a significant loss of AA in the particle free control over the $4 \mathrm{~h}$ incubation period.

samples (Figure 3). Notably, in this simplified model in the absence of GSH and UA, the protection afforded by DTPA was only approximately half of that seen using the synthetic RTLF. Increasing the DTPA concentration to 200 $\mu \mathrm{M}$ completely blocked AA depletion in this model (Figure 4). Limited, though statistically significant protection was also seen using the antioxidant enzymes superoxide dismutase and catalase (11.9\%), whilst no decrease in AA oxidation was seen with catalase alone or heat inactivated superoxide dismutase and catalase (Figure 3).

When the dung cake aqueous and organic extracts were separated the vast majority $(80.6 \%)$ of the oxidative activity was found to be associated with water-soluble components (Figure 5). The residual activity associated with the hexane extract could be completely inhibited through the co-incubation of $100 \mu \mathrm{M}$ DTPA indicating that this activity was not due to organic radicals. Consistent with these findings, dung cake aqueous extracts were shown to contain appreciable concentrations of the redox active metals $\mathrm{Fe}$ and $\mathrm{Cu}$ quantified using the chromogenic chelators bathophenantroline-disulphonate (BPS) and bathocuproine-disulphonate acid (BCS) in each of the three dung cake particle suspensions. These methods gave Fe concentrations of 7.1, 3.6, and $8.5 \mu \mathrm{g} / \mathrm{mg}$ in DC 1,2 and 3 respectively and 26.2, 26.2 and $23.8 \mu \mathrm{g} / \mathrm{mg}$ for $\mathrm{Cu}$. In comparison ROFA contained $23.7 \pm 0.30 \mu \mathrm{g} / \mathrm{mg} \mathrm{Fe}$ and $5.9 \pm 0.73 \mu \mathrm{g} / \mathrm{mg}$ of $\mathrm{Cu}$, whilst both metals were undetectable in the diesel and gasoline samples, using either chromogenic chelator. 


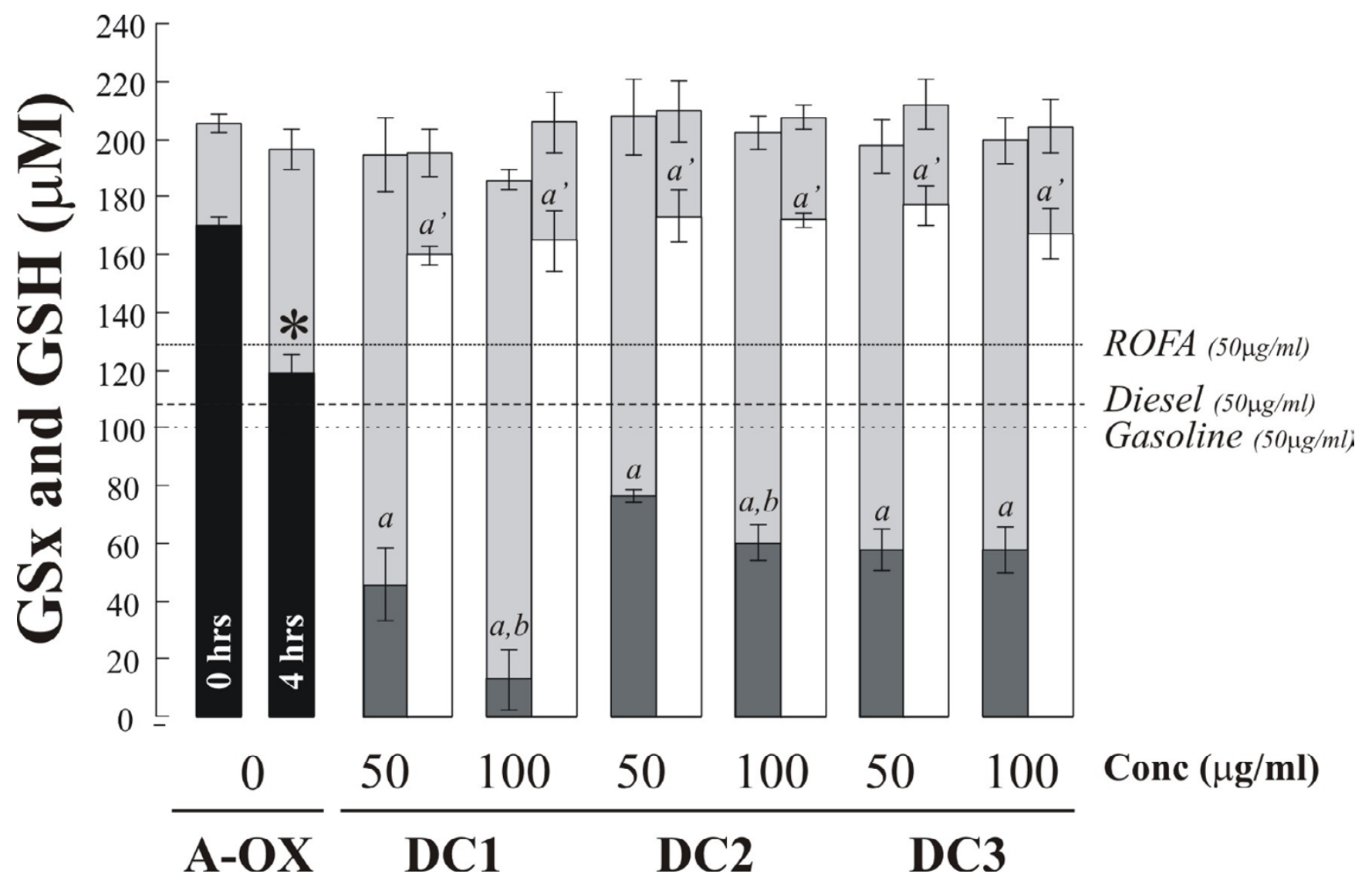

Figure 2

Total (GSx) and reduced glutathione (GSH) remaining in synthetic RTLF following a $4 \mathrm{~h}$ incubation with three separate dung cake (DC) samples at 50 and $100 \mu \mathrm{g} / \mathrm{ml}$. Reduced glutathione concentrations after $4 \mathrm{~h}$ are illustrated by dark grey bars, whilst the corresponding total glutathione concentration (GSx) are shown in light grey beneath the corresponding GSH data. The impact of coincubation with the transition metal chelator DTPA $(200 \mu \mathrm{M})$ is illustrated by the white bars, otherwise the figure is formatted as outlined in the legend to figure I with the following amendments. Notably DTPA incubation prevented not only the PMinduced loss of GSH but the background auto-oxidation seen in the particle-free controls. 'a" indicates that the concentration of GSH remaining after $4 \mathrm{~h}$ following co-incubation with DTPA was significantly greater than that in the $4 \mathrm{~h}$ particle-free control.

\section{Discussion}

Indoor air pollution poses a significant health risk worldwide. WHO estimates suggest that up to $6.5 \%$ of the annual disease burden in developing nations is attributable to the burning of solid fuels in the indoor environment [24,25]. Smoke from cooking stoves burning biomass fuels contains carbon monoxide, fine particulates, nitrogen dioxide and hydrocarbons; all at concentrations far in excess of what is considered unsafe in outdoor air [7]. In this study we investigated whether fine particles derived from the burning of the biofuel dung cake also displayed high levels of intrinsic oxidative activity relative to traffic and industrial derived PM. We wanted to examine the hypothesis that the health effects associated with exposure to biofuel derived PM were not solely a function of the high exposure concentrations but also because of their high content of redox active components.

It has been proposed that the capacity of inhaled particles to elicit inflammation and injury in the lung, as well as systemically, may be related to their capacity to cause oxidative stress [17]. In this working paradigm, inhaled particles generate oxidative stress through three inter-related pathways: first, by directly introducing oxidising species into the lung, such as redox active transition metals [16] or quinones [19] absorbed onto their surface. Second, by introducing surface absorbed PAHs that can undergo biotransformation in vivo into quinones species through the action of the cytochrome P450, epoxide hydrolase and dihydrodial dehydrogenase detoxification pathway [26] 


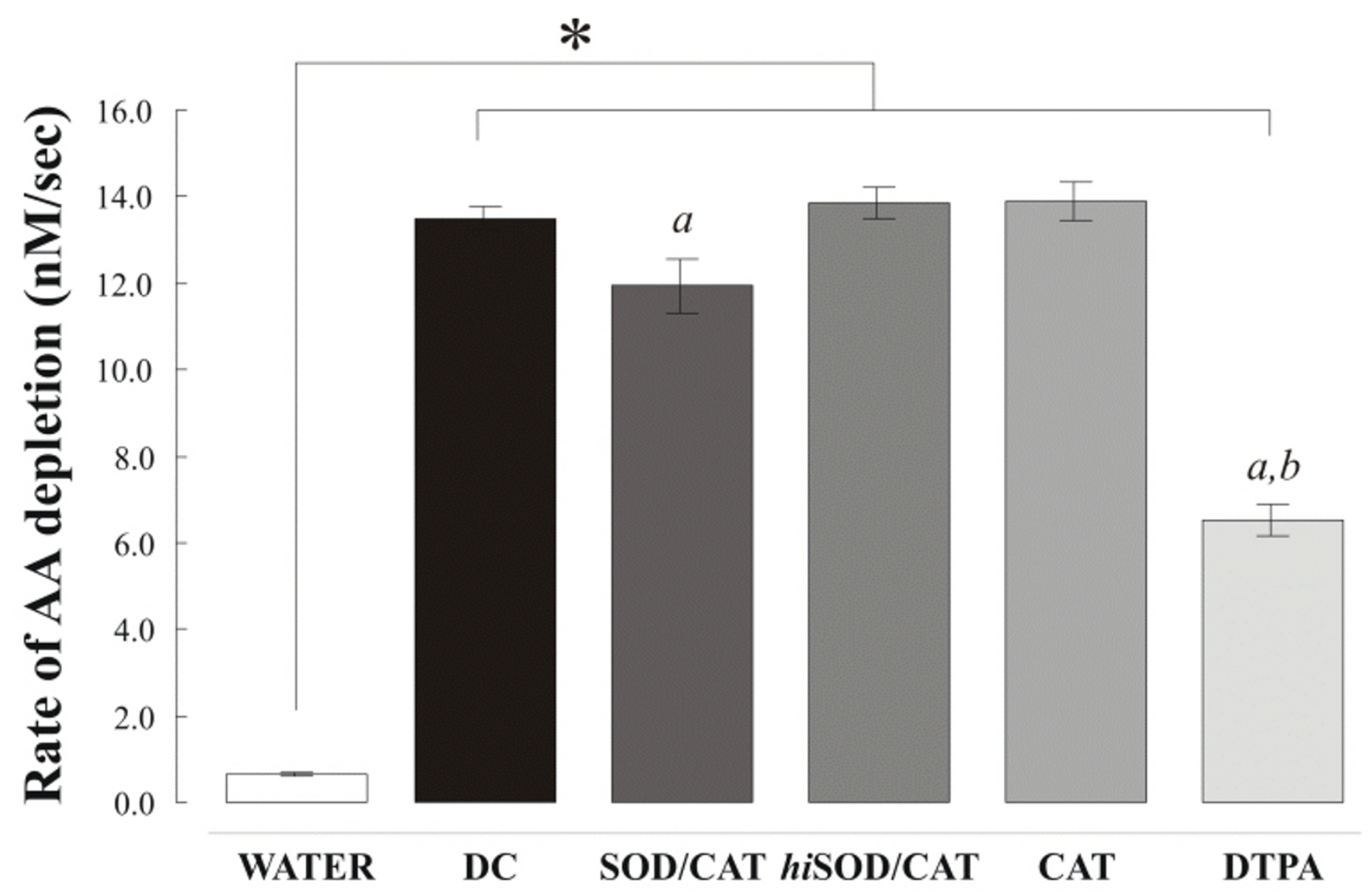

Figure 3

Rate of ascorbate consumption observed from a simple ascorbate-only solution with and without a range of metal chelation and free radical scavenger treatments. All data represent the mean (SD) of three separate experiments: $A O X=$ particle free control; $D C=$ dung cake samples $(\mathrm{I}-3$ at $50 \mu \mathrm{g} / \mathrm{ml})$; SOD/CAT = superoxide dismutase $(50 \mathrm{U} / \mathrm{mL})$ and catalase $(I 50 \mathrm{U} / \mathrm{mL}) ;$ hiSOD/CAT = heat inactivated antioxidant enzymes; CAT = catalase only $(I 50 \mathrm{U} / \mathrm{mL})$, and DTPA $(100 \mu M)$. 'a' indicates that the rate of ascorbate consumption was significantly reduced $(P<0.05)$ after SOD/CAT and DTPA treatment; ' $b$ ' that the DTPA treatment reduced the rate significantly more than the antioxidant enzyme treatment.

and finally by stimulating inflammatory cells to undergo the oxidative burst. In this final case, activation of inflammatory cells may be triggered by endotoxin on the surface of inhaled particles [27], futile phagocytic processing of PM [28], or by the up-regulation of redox sensitive transcription factors directing the synthesis of pro-inflammatory cytokines [29]. The integrated sum of all these processes can be considered the 'total' oxidative activity of the particle.

In this study we measured PM oxidative activity using an in vitro screening procedure that assessed the capacity of PM associated pro-oxidant components (metals and quinones) to deplete physiologically relevant antioxidants, ascorbate, urate and reduced glutathione from a synthetic model of the RTLF [21,22]. This 'intrinsic' activity, meas- ured in a cell free system, only reflects the oxidative activity attributable to redox active metals and quinone compounds and not 'latent' activities that may be associated with PAHs or endotoxin. With this caveat, we found PM samples derived from the combustion of dung cake to be significantly more active, on an equal mass basis, than either metal-rich ROFA or PAH-rich vehicle exhaust PM, despite the greater surface area of these samples. This activity was manifest by the capacity of the PM suspensions to deplete both AA and GSH from synthetic RTLF. Notably, the endotoxin and PAH content of dung cake and other biofuels have been shown to be high [24,30] suggesting that their 'total' oxidative activity is likely to be far in excess of that associated with traffic derived PM. This very high oxidative activity in animal dung combustion particles supports studies demonstrating increased 


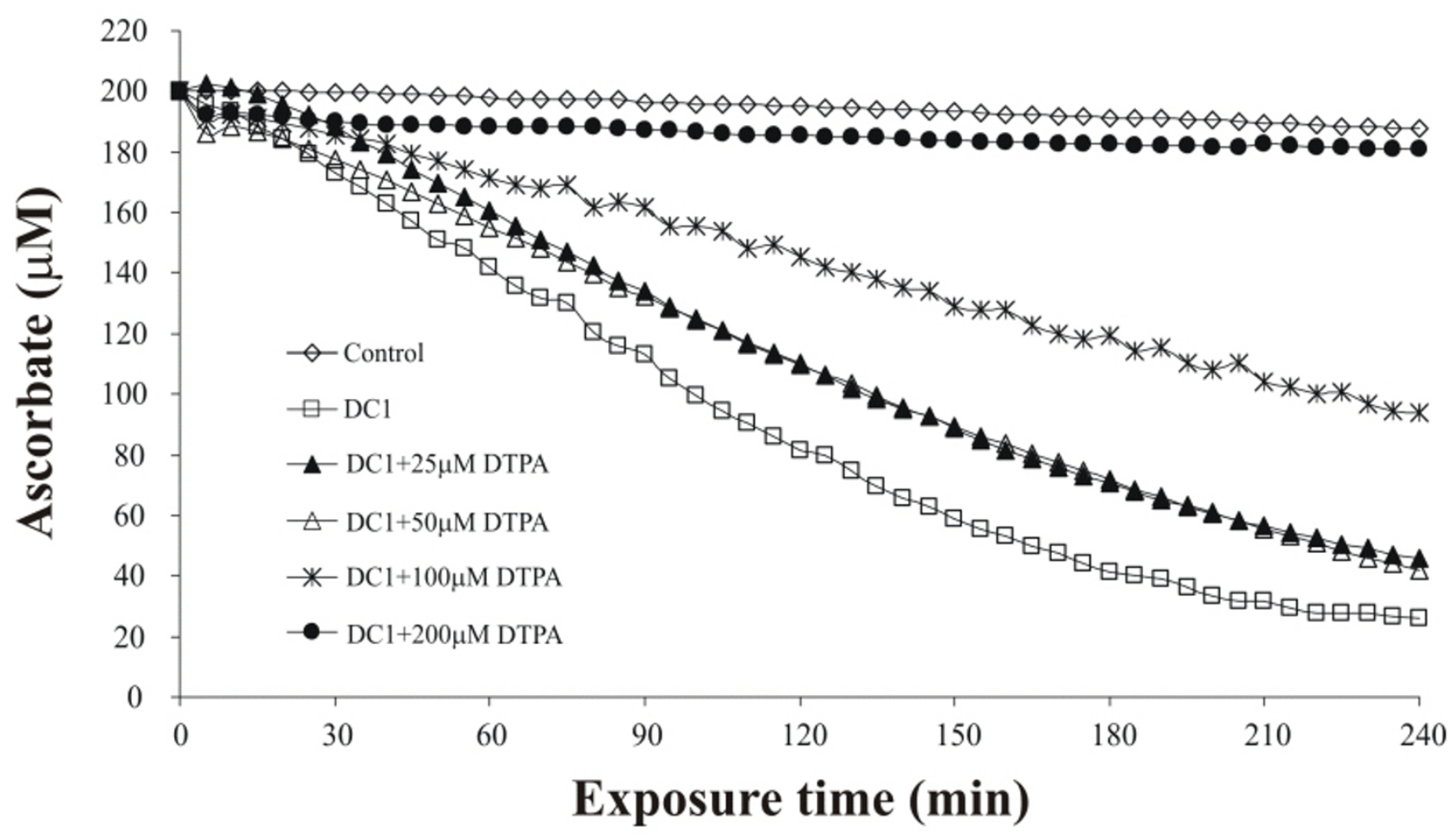

\section{Figure 4}

Time dependent loss of ascorbate associated with incubation of DC at $50 \mu \mathrm{g} / \mathrm{ml}$ at varying concentrations of DTPA. Each trace represents the mean of three separate experiments. The SDs on each mean value are not illustrated for graphical simplicity but were less than $5 \%$ of the mean values in all cases.

pulmonary toxicity in mice following instillation of particles derived from dried municipal sewage combustion, relative to coal alone [31].

The depletion of both AA and GSH from the model was prevented by co-incubation with the metal chelator diethylenetriaminepentaacetate (DTPA) indicating that the losses observed were driven by redox active metals such as $\mathrm{Fe}, \mathrm{Cu}, \mathrm{Ni}$, and $\mathrm{Cr}$. DTPA has five acetate groups linked to a molecular backbone that permits it to form tight complexes with a broad range of metals, preventing them from catalysing damaging oxidation reactions. Desferoxamine (DFO) was not used in these studies as it has been reported to reduce chelated $\mathrm{Cu}$ that would have resulted in interpretive difficulties when examining its protective role in mixtures of soluble metals [32]. The contribution of superoxide and hydrogen peroxide to the observed antioxidant losses was examined in co-incubation experiments using the antioxidant enzymes $\mathrm{Cu}$, $\mathrm{Zn}$ superoxide dismutase (SOD) and catalase (CAT). Limited protection was observed with these enzymatic antioxidants suggesting that the contribution of these reactive oxygen species to the ascorbate and glutathione losses was minor compared with those attributable to their direct oxidation during the reduction of $\mathrm{Fe}^{3+}$ and $\mathrm{Cu}^{2+}$.

Thus we conclude that AA and GSH oxidation occurred predominately by their direct reduction of $\mathrm{Fe}^{3+}$ to $\mathrm{Fe}^{2+}$ and $\mathrm{Cu}^{2+}$ to $\mathrm{Cu}^{+}$. The superoxide formed by the subsequent oxidation of ferric and cupric ions could undergo dismutation to hydrogen peroxide, reduce $\mathrm{Fe}^{3+}$ and $\mathrm{Cu}^{2+}$, or oxidise ascorbate, urate or glutathione within the synthetic RTLF. As the reaction rate between $\mathrm{Fe}^{3+}$ and superoxide $\left(1.5 \times 10^{8} \mathrm{M}^{-1} \mathrm{~s}^{-1}\right)$ greatly exceeds that its dismutation at physiological pH $\left(5.4 \times 10^{5} \mathrm{M}^{-1} \mathrm{~s}^{-1}, \mathrm{pH} 7.4\right)$ it seems likely that the former reaction predominated, especially as little loss of ascorbate or glutathione could be attributed to superoxide or hydrogen peroxide production. Interestingly, we saw no evidence of urate depletion, despite the importance of this antioxidant in protecting the airway against oxidant gases [33], peroxynitrite [34] and hydroxyl radicals [35]. The rate of the reaction of urate with hydroxyl radicals $\left(7.2 \times 10^{9} \mathrm{M}^{-1} \mathrm{~s}^{-1}, \mathrm{pH} 6-7\right)$ is broadly similar to that of both ascorbate $\left(1.6 \times 10^{9}-1.1\right.$ 

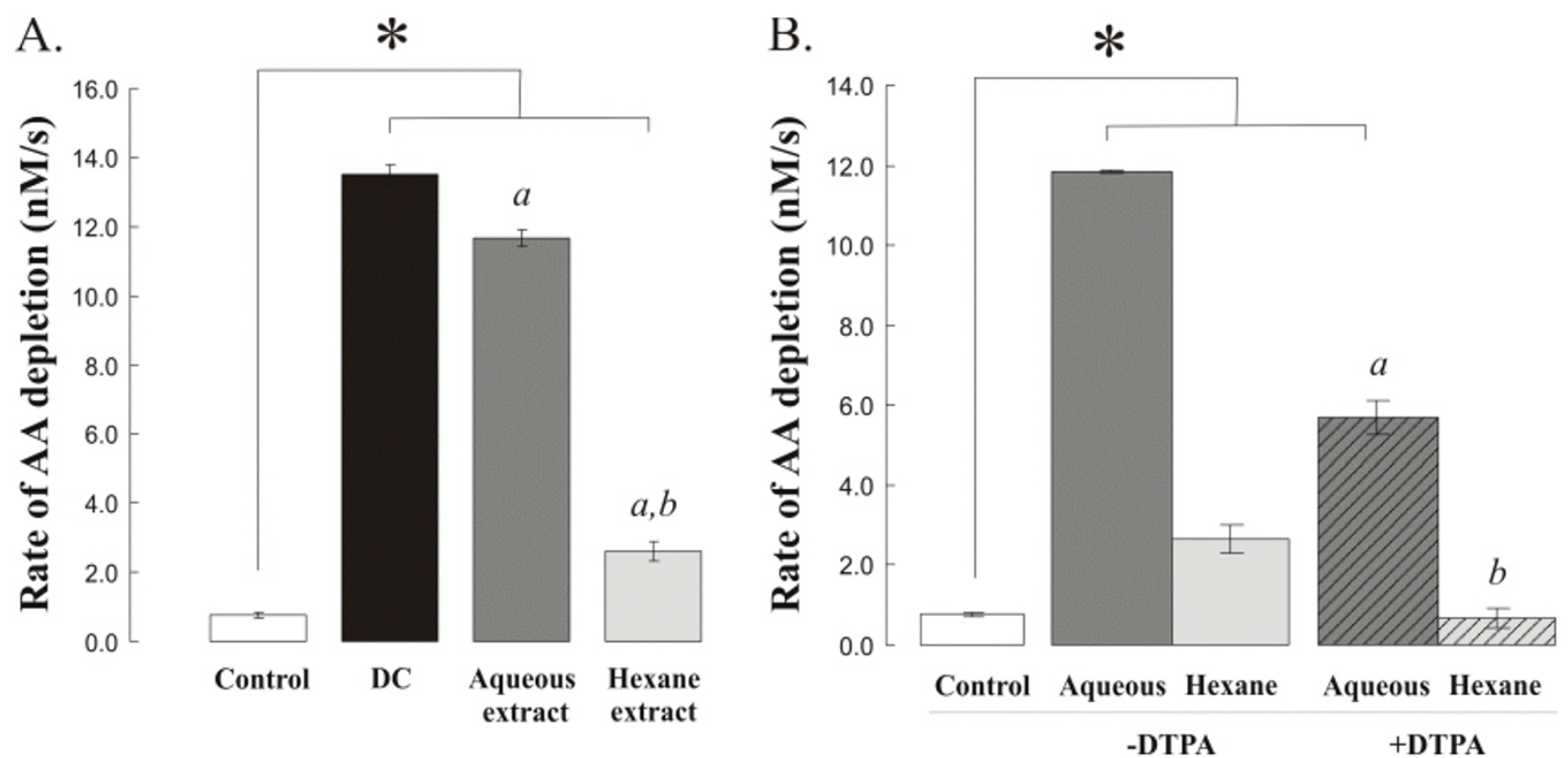

\section{Figure 5}

Rates of ascorbate consumption seen with aqueous and organic extracts of dung cake (DC) particle extracts. All data represent the mean (SD) of three separate experiments. '*' Indicates that the rate of AA depletion seen with the complete, aqueous and organic dung cake extracts was significantly greater $(P<0.05)$ than that observed in the particle free control; 'a' that the activity of the aqueous and organic extracts were significantly less than the complete extract; and, 'b' that the rate of AA depletion by the organic extract, with or without DTPA, was less than that seen with the aqueous fraction.

$\left.\times 10^{10} \mathrm{M}^{-1} \mathrm{~s}^{-1}, \mathrm{pH} 7-7.4\right)$ and glutathione $\left(9.0 \times 10^{9}-1.3\right.$ $\times 10^{10} \mathrm{M}^{-1} \mathrm{~s}^{-1}, \mathrm{pH} 8$ and 7.8 , respectively). Thus the absence of UA depletion in this model supported the contention that superoxide dismutation to hydrogen peroxide was not occurring to any great extent, with little evidence of hydroxyl radical generation. Whilst the redox potentials of UA and AA at $\mathrm{pH} 7\left(\mathrm{E}^{\circ 1}=590\right.$ and $282 \mathrm{mV}$ respectively) [36] may suggest that the urate radical could be reduced back to UA at the expense of AA we do not believe that this occurred, as removal of urate from the RTLF had no impact on the observed rate of ascorbate depletion (data not shown).

We also observed that the capacity of DTPA to inhibit ascorbate oxidation was significantly reduced in the ascorbate only incubation experiment: only $100 \mu \mathrm{M}$ being required for full inhibition in the complete synthetic RTLF as opposed to $200 \mu \mathrm{M}$ in the ascorbate only RTLF model. This finding may imply that either GSH or UA is limiting the bioavailability of $\mathrm{Fe}$, either through chelation, as has been proposed for UA [37], or by interfering with the capacity of AA to solubilise ferric iron from the particle surface [16]. We are currently investigating these potential actions of UA and GSH. Irrespective of this, when the con- centration of DTPA was increased in the AA only model, all AA oxidation was blocked indicating the absence of a quinone-dependent activity in the DC particles. This contention was supported by the observation that only a fraction of the measured oxidative activity was present in organic DC extracts. Whilst other groups have emphasised the importance of PM associated quinones/hydroquinones in the oxidative activity of ambient PM [19] our data would tend to emphasise metal content as the major determinant of DC oxidative activity. Clearly the contribution of metal and organic components to PM oxidative activity may vary depending on its source. In addition it is also likely that the age and storage conditions of the filters used in this study resulted in losses of potentially reactive organic species. These cautionary caveats only further emphasise that we are probably underestimating the 'true' oxidative capacity of freshly generated DC particulates.

As these findings implicated redox active metals in the oxidation process we measured the bioavailable $\mathrm{Fe}$ and $\mathrm{Cu}$ content of the DC particles. This measurement included reduced and oxidised forms of these metals, both water-soluble and surface mobilisable through ligation to the chromogenic chelators bathophenantroline- 
disulphonate (BPS) [38] and bathocuproine-disulphonate acid (BCS) [39]. Using these approaches we detected considerable $\mathrm{Fe}$ and $\mathrm{Cu}$ content. The especially high content of $\mathrm{Cu}$ is likely to explain extensive glutathione oxidation observed with the dung cake samples, due to copper's high reactivity toward this antioxidant [18], as well as the lack of reactivity of the ROFA sample toward GSH. It should be noted, however, that the variation in the content of these metals in the three DC samples did not match their observed variation in oxidative activity implying that $\mathrm{Fe}$ and $\mathrm{Cu}$ were not the sole determinates of the observed activity. The compositional data pertaining to the ROFA sample $\left(\mathrm{PM}_{2.5}\right)$, used in the current study have been described previously $[23,40]$ using ICP-MS. These analyses have confirmed the relatively high concentrations of total $\mathrm{Fe}$, and low concentrations of $\mathrm{Cu}$ in the ROFA sample derived from the burning of heavy fuel oil $\left(\mathrm{N}^{\circ} 5\right)$. These metals are however less abundant in the ROFA sample than either vanadium $(58.6 \mu \mathrm{g} / \mathrm{g})$ or nickel $(10.6 \mu \mathrm{g} / \mathrm{g})$. In contrast, ICP-MS analysis of both the gasoline and diesel samples revealed these metals to be below detectable limits [41], which concurs with their low reactivity in this assay system and these measurements made using the chromogenic chelators. Parallel ICP-MS analysis of dung cake PM obtained under identical burn conditions has also subsequently revealed appreciable concentrations of the redox active metals $\mathrm{Ni}$ and $\mathrm{Cr}$ (45 and 40 $\mu \mathrm{g} / \mathrm{g}$ PM, respectively) in these samples, but no detectable $\mathrm{V}$. This elemental analysis will be described in detail in a subsequent manuscript.

The high metal content of the dung cake may reflect both the presence of biological metals; especially $\mathrm{Fe}$ and $\mathrm{Cu}$ in dung [42], as well as metals associated with the local soil with which the animal dung is mixed to make the bricklets. These data therefore support the initial hypothesis that fine particles derived from the controlled burning of dung cake are highly oxidative in nature due to their content of redox active metals.

\section{Conclusion}

These data demonstrate that fine particles derived from the burning of the biomass fuel dung cake are highly oxidising. This activity appears to be largely related to their content of redox active metals, with the caveats mention above. As oxidative activity is a biologically meaningful index, the high activity associated with dung cake fine particles allied to their high concentrations in homes using dung cake fuel emphasises their potential negative health impact.

\section{Methods}

\section{Sample Collection and Filter extraction}

Dung-cake was obtained from Eksaal, near Mumbai. Dung cake has a high ash content, $25-30 \%$ and is made by mixing dung with mud/clay and straw to improve its mechanical strength. It is then patted down, moulded and sun-dried for $24 \mathrm{~h}$, which achieves moisture content of 7$8 \%$. As dung-cake combustion results in copious particle emissions a sampling rate of 3-4 L per minute was used in the particle sampler, and a burn time of $12 \mathrm{~min}$, to ensure no clogging of the Teflon filter substrates used for particle collection. The particle sampler employed had a cyclone inlet to exclude particles larger than $2.6 \mu \mathrm{m}$ diameter [4]. All Teflon filters were conditioned for 12 -h at $50 \% \mathrm{RH}$ and $25^{\circ} \mathrm{C}$ prior to weighing. Filters were shipped to the UK where the PM was extracted from the Teflon matrix using a standardized vortexing and sonication protocol into Chelex-treated water contain 5\% methanol, $\mathrm{pH} 7.0$ [21]. All subsequent dilutions of this particle solution were also performed in Chelex-treated water contain 5\% methanol, pH 7.0. Diesel and gasoline particles in the fine mode $(0.1-2.5 \mu \mathrm{m})$ were obtained from Professor Thomas Sandstrom (University Hospital, Umeå, Sweden) derived from idling diesel (Volvo TD45, 4.5 L, 4cylinders, 1991 ) and gasoline (2.0 L "Opel Omega" with a catalyst from 1989) engines. Details of the diesel fuel used have been published previously [43] whilst the gasoline engine utilized 95-octane gasoline. Residual fly ash was kindly donated by Professor Ken Donaldson (University of Edinburgh, Scotland, UK). Diesel, gasoline and ROFA PM samples were resuspended in Chelex-treated water contain 5\% methanol, $\mathrm{pH} 7.0$ at the required concentration and the $\mathrm{pH}$ of the resultant suspension adjusted to neutral $\mathrm{pH}$.

Particle Incubations and Measurement of Antioxidant Loss For the initial experiments dung cake extracts were diluted to either 100 or $50 \mu \mathrm{g} / \mathrm{ml}$ and incubated at $37^{\circ} \mathrm{C}$ in synthetic RTLF (200 $\mu \mathrm{M}, \mathrm{AA}, \mathrm{UA}$ and GSH, pH7.0) for a period of $4 \mathrm{~h}$. After incubation, samples were either acidified with metaphosphoric acid to a final concentration of $5 \%(\mathrm{w} / \mathrm{v})$ for UA and AA measurement or diluted into 100 $\mathrm{mM}$ phosphate buffer for determination of GSH. Antioxidant determinations have been described previously [21]. Subsequent inhibitor studies were performed at PM concentrations of $50 \mu \mathrm{g} / \mathrm{ml}$ by following the loss of AA (starting concentration $200 \mu \mathrm{M}, \mathrm{pH} 7.0,37^{\circ} \mathrm{C}$ ) at $265 \mathrm{~nm}$ over a $4 \mathrm{~h}$ time course with readings every 5 minutes. Incubations were performed with dung cake extracts only, as well as in the presence of a range of free radical scavengers and transition metal chelators: $\mathrm{SOD} / \mathrm{CAT}=$ superoxide dismutase $(50 \mathrm{U} / \mathrm{mL})$ and catalase $(150 \mathrm{U} / \mathrm{mL})$; hiSOD/CAT $=$ heat inactivated antioxidant enzymes; CAT = catalase only $(150 \mathrm{U} / \mathrm{mL})$, and DTPA = Diethylenetriamine pentaacetate $(200 \mu \mathrm{M})$.

\section{Hexane extractions}

$1 \mathrm{ml}$ of each dung cake particle suspension at $55.6 \mu \mathrm{g} / \mathrm{ml}$ was vortexed hard for 2 minutes with an equal volume of HPLC grade hexane. At the end of this mixing period the 
organic and aqueous phases were separated, and the former dried under nitrogen at room temperature. The hexane extract was then resuspended according to the standard protocol in an equal volume of Chelex-treated water containing 5\% methanol.

\section{Total Fe and $\mathrm{Cu}$ determinations}

Total iron concentrations in the particle suspensions were determined using the $\mathrm{Fe}^{2+}$-specfic chromogenic chelator, bathophenantroline disulphonate (BPS) [38]. DC particle suspensions $(55.6 \mu \mathrm{g} / \mathrm{ml})$ were prepared in Chelex-100

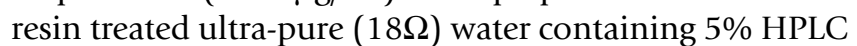
grade methanol ( $\mathrm{pH} 7)$. These samples were then incubated with BPS $(1 \mathrm{mM})$ in the presence of $10 \mathrm{mM}$ ascorbate (final $\mathrm{pH} 4$ ) for 30 minutes in the dark. These samples were then briefly vortexed and then centrifuged at 13,000 rpm for 15 minutes. The absorbance of the BPS-Fe complex was then determined in the particle free supernatant at $535 \mathrm{~nm}$. Iron concentrations were determined against a standard curve of ferrous ammonium sulphate $(0-50 \mu \mathrm{M})$ in ultrapure water, 5\% methanol, in the presence of $10 \mathrm{mM}$ ascorbic acid. Particle free and filter blanks were also ran in parallel to the extracted dung cake samples and these background concentrations subtracted from the determined dung cake Fe concentrations. A further blank containing the dung cake suspension with ascorbate but in the absence of BPS was also included and the background absorbance subtracted from the observed values in the dung cake samples. Total copper was similarly determined using the $\mathrm{Cu}+$-specific chromogenic chelator bathocuproine-disulphonate at $483 \mathrm{~nm} \mathrm{[39],} \mathrm{with}$ the following amendments: the final ascorbate concentration in the samples and standards was $1 \mathrm{mM}$ and the $\mathrm{pH}$ 7.0. Coppers concentrations were determined a standard curve of copper sulphate $(0-20 \mu \mathrm{M})$ prepared in Chelex100 resin treated water.

\section{Statistical analysis}

All data are expressed throughout as means with SD. Specific experimental details are summarised the each Figure legend. Experimental group comparisons were performed using two way repeated measures ANOVA. Post-hoc comparisons of group means were performed using the Student-Newman-Kuels test. All statistical analyses were performed using SPSS for windows, version 11.5 or the Unistat Exel plug-in, version 4.53.

\section{List of Abbreviations used \\ AOX Antioxidant}

AA Ascorbate

UA Urate

GSH Reduced glutathione
GSSG Glutathione disulphide

RTLF Respiratory tract lining fluid

DC Dung cake

DFO Desferoxamine

BPS Bathophenantroline-disulphonate

BCS Bathocuproine-disulphonate

DPTA Diethylene triamine pentaacetate

SOD Superoxide dismutase

hiSOD Heat inactivated superoxide dismutase

CAT Catalase

PAH Polyaromatic hydrocarbons

PM Particulate matter

WHO World Health Organisation

\section{Competing interests}

Ian S Mudway: None

Sean T Duggan: None

Chandra Venkataraman: None

Frank J Kelly: None

Jonathon Grigg: None

Authors' contributions

Ian S Mudway: Study design and experimental work, data analysis, preparation of manuscript

Sean T Duggan: Study design and experimental analysis

Chandra Venkataraman: Collection of particle samples from dung cake combustion

Gazala Habib: Collection of particle samples from dung cake combustion

Frank J Kelly: Study conception and design, manuscript review

Jonathon Grigg: Study conception and design 


\section{Acknowledgements}

The authors would like to express their gratitude to Professors Thomas Sandstrom and Ken Donaldson for their gift of the ROFA, diesel and gasoline particles used as control particles in this study.

\section{References}

I. Barnes DF, Openshaw K, Smith KR, van der Plas R: What makes people cook with improved biomass stoves? A Comparative International Review of Stove Programs. World Bank Technical Paper 1994, 242:. World Bank

2. Balakrishnan K, Sankar S, Parikh J, Padmavathi R, Srividya K, Venugopal V, Prasad S, Pandey VL: Daily average exposures to respirable particulate matter from combustion of biomass fuels in rural households of southern India. Environ Health Perspect 2002, I I0(I I): I069-75.

3. Raiyani CV, Jani JP, Desai NM, Shah SH, Shah PG, Kashyap SK: Assessment of indoor exposure to polycyclic aromatic hydrocarbons for urban poor using various types of cooking fuels. Bull Environ Contam Toxicol 1993, 50(5):757-63.

4. Venkataraman C, Rao GUM: Emission factors of carbon monoxide and size-resolved aerosols from biofuel combustion. Environ Sci Technol 200I, 35(I 0):2100-7.

5. Smith KR, Samet JM, Romieu I, Bruce N: Indoor air pollution in developing countries and acute lower respiratory infections in children. Thorax 2000, 55(6):518-32

6. Ezzati M, Kammen DM: The health impacts of exposure to indoor air pollution from solid fuels in developing countries: knowledge, gaps, and data needs. Environ Health Perspect 2002, I | 0( I I): 1057-68.

7. US Environmental Protection Agency: National Ambient Air Quality Standards. [http://www.epa.gov/air/criteria.html].

8. Chen $\mathrm{BH}$, Hong CJ, Pandey MR, Smith KR: Indoor air pollution in developing countries. World Health Stat $Q$ 1990, 43(3): |27-38.

9. Mishra V, Retherford RD: Cooking smoke increases the risk of acute respiratory infection in children. Natl Fam Health Surv Bull 1997:1-4.

10. Mishra V: Indoor air pollution from biomass combustion and acute respiratory illness in preschool age children in Zimbabwe. Int J Epidemiol 2003, 32(5):847-53.

II. Viegi G, Simoni M, Scognamiglio A, Baldacci S, Pistelli F, Carrozzi L, Annesi-Maesano I: Indoor air pollution and airway disease. Int J Tuberc Lung Dis 2004, 8( I 2): | 40 I-I 5.

12. Bruce N, Perez-Padilla R, Albalak R: Indoor air pollution in developing countries: a major environmental and public health challenge. Bull World Health Organ 2000, 78(9): I078-92.

13. Kulkarni NS, Prudon B, Panditi SL, Abebe Y, Grigg J: Carbon loading of alveolar macrophages in adults and children exposed to biomass smoke particles. Science of the Total Environment in press.

14. Donaldson K, Stone V: Current hypotheses on the mechanisms of toxicity of ultrafine particles. Ann Ist Super Sanita 2003, 39(3):405-10.

15. Xia T, Korge P, Weiss JN, Li N, Venkatesen MI, Sioutas C, Nel A: Quinones and aromatic chemical compounds in particulate matter induce mitochondrial dysfunction: implications for ultrafine particle toxicity. Environ Health Perspect 2004, I I 2( I 4): | 347-58.

16. Aust AE, Ball JC, Hu AA, Lighty JS, Smith KR, Straccia AM, Veranth JM, Young WC: Particle characteristics responsible for effects on human lung epithelial cells. Res Rep Health Eff Inst 2002: I-65.

17. Roberts ES, Richards JH, Jaskot R, Dreher KL: Oxidative stress mediates air pollution particle-induced acute lung injury and molecular pathology. Inhal Toxicol 2003, I 5(I3): I327-46.

18. Stohs SJ, Bagchi D: Oxidative mechanisms in the toxicity of metal ions. Free Radic Biol Med 1995, I 8(2):321-36.

19. Squadrito GL, Cueto R, Dellinger B, Pryor WA: Quinoid redox cycling as a mechanism for sustained free radical generation by inhaled airborne particulate matter. Free Radic Biol Med 200I, 3 I(9): I | 32-8.

20. Takizawa H, Abe S, Okazaki H, Kohyama T, Sugawara I, Saito Y, Ohtoshi T, Kawasaki S, Desaki M, Nakahara K, Yamamoto K, Matsushima K, Tanaka M, Sagai M, Kudoh S: Diesel exhaust particles upregulate eotaxin gene expression in human bronchial epithelial cells via nuclear factor-kappa B-dependent pathway. Am J Physiol Lung Cell Mol Physiol 2003, 284(6):L I055-62.
21. Mudway IS, Stenfors N, Duggan ST, Roxborough H, Zielinski H, Marklund SL, Blomberg A, Frew AJ, Sandstrom T, Kelly FJ: An in vitro and in vivo investigation of the effects of diesel exhaust on human airway lining fluid antioxidants. Arch Biochem Biophys 2004, 423(I):200-12.

22. Mudway IS, Kelly FJ: Modeling the interactions of ozone with pulmonary epithelial lining fluid antioxidants. Toxicol Appl Pharmacol 1998, I 48(I):91-100.

23. Miller CA, Linak WP, King C, Wendt JOL: Fine particle emissions from heavy fuel oil combustion in a firetube package boiler. Combust Sci Technol 1998, I 34:477-502.

24. World Health Organisation: World Health Report. Geneva, WHO; 200I.

25. Smith KR, Mehta S: The burden of disease from indoor air pollution in developing countries: comparison of estimates. Int J Hyg Environ Health 2003, 206(4-5):279-89.

26. Bonvallot V, Baeza-Squiban A, Baulig A, Brulant S, Boland S, Muzeau F, Barouki R, Marano F: Organic compounds from diesel exhaust particles elicit a proinflammatory response in human airway epithelial cells and induce cytochrome p450 IA I expression. Am J Respir Cell Mol Biol 200 I, 25(4):5 I5-2I.

27. Monn C, Naef R, Koller T: Reactions of macrophages exposed to particles < 10 microm. Environ Res 2003, 9 I (I):35-44.

28. Soukup JM, Becker S: Human alveolar macrophage responses to air pollution particulates are associated with insoluble components of coarse material, including particulate endotoxin. Toxicol Appl Pharmacol 200 I, I 7 I(I):20-6.

29. Bonvallot V, Baulig A, Boland S, Marano F, Baeza A: Diesel exhaust particles induce an inflammatory response in airway epithelial cells: involvement of reactive oxygen species. Biofactors 2002, I6(1-2): I5-7.

30. Madsen AM, Martensson L, Schneider T, Larsson L: Microbial dustiness and particle release of different biofuels. Ann Occup Hyg 2004, 48(4):327-38.

3I. Fernandez A, Wendt JO, Cenni R, Young RS, Witten ML: Resuspension of coal and coal/municipal sewage sludge combustion generated fine particles for inhalation health effects studies. Sci Total Environ 2002, 287(3):265-74.

32. Van Reyk DM, Dean RT: The iron-selective chelator desferal can reduce chelated copper. Free Radic Res 1996, 24(I):55-60.

33. Mudway IS, Blomberg A, Frew AJ, Holgate ST, Sandstrom T, Kelly FJ: Antioxidant consumption and repletion kinetics in nasal lavage fluid following exposure of healthy human volunteers to ozone. Eur Respir J 1999, I 3(6): | 429-38.

34. Squadrito GL, Cueto R, Splenser AE, Valavanidis A, Zhang $H$, Uppu RM, Pryor WA: Reaction of uric acid with peroxynitrite and implications for the mechanism of neuroprotection by uric acid. Arch Biochem Biophys 2000, 376(2):333-7.

35. Becker BF: Towards the physiological function of uric acid. Free Radic Biol Med 1993, I 4(6):6I5-31.

36. Buettner GR: The pecking order of free radicals and antioxidants: lipid peroxidation, alpha-tocopherol, and ascorbate. Arch Biochem Biophys 1993, 300(2):535-43.

37. Davies KJ, Sevanian A, Muakkassah-Kelly SF, Hochstein P: Uric acidiron ion complexes. A new aspect of the antioxidant functions of uric acid. Biochem J 1986, 235(3):747-54.

38. Nilsson UA, Bassen M, Savman K, Kjellmer I: $\mathbf{A}$ simple and rapid method for the determination of "free" iron in biological fluids. Free Radic Res 2002, 36(6):677-84

39. Cecconi I, Moroni M, Vilardo PG, Dal Monte M, Borella P, Rastelli G, Costantino L, Garland D, Carper D, Petrash JM, Del Corso A, Mura $U$ : Oxidative modification of aldose reductase induced by copper ion. Factors and conditions affecting the process. Biochemistry 1998, 37(40): 14167-74.

40. Hoffman GP, Huggins FE, Shah N, Huggins R, Pugmire RJ, Meuzelaar HLC, Seehra MS, Manivannan A: Characterisation of fine particulate matter produced by combustion of residual fuel oil. J Air \& Waste Manage Assoc 2000, 50: I I06-I I I4.

4I. Bloeman HJT, Gerlofs-Nijland ME, Janssen NAH, Sandstrom T, van Bree L, Cassee FR: Chemical characterisation and source apportionment estimates of particulate matter collected within the framework of the EU project HEPMEAP. RIVM report 863001002/2005 2005.

42. Anthony WB: Animal waste value - nutrient recovery and utilization. J Anim Sci 1971, 32(4):799-802. 
43. Salvi S, Blomberg A, Rudell B, Kelly F, Sandstrom T, Holgate ST, Frew $A$ : Acute inflammatory responses in the airways and peripheral blood after short-term exposure to diesel exhaust in healthy human volunteers. Am J Respir Crit Care Med 1999, 159(3):702-9.

Publish with Bio Med Central and every scientist can read your work free of charge

"BioMed Central will be the most significant development for disseminating the results of biomedical research in our lifetime. " Sir Paul Nurse, Cancer Research UK

Your research papers will be:

- available free of charge to the entire biomedical community

- peer reviewed and published immediately upon acceptance

- cited in PubMed and archived on PubMed Central

- yours - you keep the copyright

Submit your manuscript here:

http://www.biomedcentral.com/info/publishing_adv.asp
BioMedcentral 